\title{
Relevance of Gastronomy in the Tourism of a World Heritage Site: The Case of Sucre (Bolivia)
}

\author{
Miguel Jesús Medina-Viruel ${ }^{1}{ }^{(0)}$, Gema Gomez Casero ${ }^{1}{ }^{1}$, Pedro Antonio Fuentes Jiménez ${ }^{2}$ and \\ Francisco González Santa Cruz ${ }^{3, *(D)}$ \\ 1 Department of Applied Economics, Agrifood Campus of International Excellence, University of Cordoba, \\ E-14002 Córdoba, Spain; mjmedina@uco.es (M.J.M.-V.); ggomezfuentes@uco.es (G.G.C.) \\ 2 Coordinator of the Doctorate in Business Management, Royal Mayor and Pontifical, University of San \\ Francisco Xavier in Chuquisaca, Sucre, Bolivia; fuentespedroantonio@gmail.com \\ 3 Department of Business Organization, Agrifood Campus of International Excellence, University of Cordoba, \\ E-14002 Córdoba, Spain \\ * Correspondence: td1gosaf@uco.es
}

Received: 11 September 2019; Accepted: 19 November 2019; Published: 20 November 2019

check for updates

\begin{abstract}
Recently, gastronomy has become one of the most important tourist attractions for cities as well as for rural areas. In this respect, tourists look for authenticity in the gastronomy heritage of these destinations, making it, thusly, a motivation for visiting the place. This research presents a segmentation of the tourists who visit Sucre (Bolivia), on the basis of a higher or lower interest in the gastronomy of the city. The results extracted from the research highlight the existence of three tourist segments with different attitudes regarding gastronomic experiences. Additionally, it notes the importance that a specific type of tourist places on discovering and better understanding the gastronomy of a city as part of its cultural heritage.
\end{abstract}

Keywords: gastronomic tourism; World Heritage; segmentation; perceived value; gastronomic attributes; Sucre; Bolivia

\section{Introduction}

Currently, the level of demand from tourists has increased, especially so in relation to aspects such as the search for experiences on their travels. Therefore, new types of tourism have appeared with the aim of satisfying the search for experiences, such as enotourism, olive oil tourism, and culinary tourism. With this in mind, culinary tourism goes far beyond the simple matter of satisfying the physiological need that travellers have to feed themselves as, occasionally, it is an opportunity to discover the local culture, traditions, customs, or social relationships of this community by means of its gastronomy itself (Björk and Kauppinen-Räisänen 2016; Okumus et al. 2018; Privitera et al. 2018). As a result, this leads to a different way of understanding the cultural legacy of a specific destination.

Gastronomy makes the culture of a place unique due to the variety of recipes, the mixture of aromas, the different ingredients used, the methods of preparation, and the different flavours. A clear example of gastronomic heritage is found in Latin America, whose cuisine is recognised more and more and is in higher demand due to the origins of its recipes as well as its continuing innovation (Nelson 2016). However, when attaining international culinary recognition, it is essential to pay attention to specific actions such as, for example, carrying out the promotion of the different gastronomic practices in order to, thusly, achieve differentiation in terms of other competing destinations in this branch of tourist types (Tsai and Wang 2017). Notwithstanding, so as to achieve this recognition, local gastronomy should not only differentiate itself from the rest but also provide an appropriate number of dining 
establishments that share this philosophy with the aim of the visitor having a gastronomic experience and, therefore, feeling that they have had a unique experience (Björk and Kauppinen-Räisänen 2016).

The aim of this study is the completion of a segmentation of tourists who visited the city of Sucre (Bolivia), whose historic centre was declared a World Heritage Site in 1991, in accordance with the importance they place on gastronomy during their travels. In order to carry out the segmentation, the model of Björk and Kauppinen-Räisänen (2016) was followed, with it being one of the models of reference in this field. This model segments tourists according to their interest in gastronomy into three different groups: experiencers, enjoyers, and survivors. Therefore, and on the basis of this segmentation, this research analyses the socio-demographic profile of the visitors and their perception of the gastronomy of the city of Sucre.

The city of Sucre is recognised in Bolivia for its extensive culinary variety that is characterised by an appropriate balance between culinary tradition and the more modern experiences of cooking design. Among the dishes that form part of its gastronomic variety, those that stand out are known as Modongo, Karapecho, Chorizo Chiquisaqueño, Sullka, Picante mixto, Pique Macho, and Cazuela de Mani, among others. In addition to an extensive list of typical dishes from the cuisine of the Chuquisaca region, there are several restaurants in the city that are highlighted due to their diverse culinary range. Among them, restaurants such as 7 Lunares, El Cuchillo, El Huerto, Lo Nuestro, and Bienmesabe stand out because of their excellence. All of this wealth in gastronomic presentations and culinary establishments converts Sucre into another gastronomic capital of Bolivia (being named as such by the Plurinational Legislative Assembly of Bolivia on the 28th of December 2011, by means of Law No. 217), which recognises the culinary diversity of the regions, provinces, and municipalities of Chuquisaca.

\section{Literature Review}

The relationship between gastronomy and tourism is a topic that is addressed by authors from different viewpoints. In this research, we are going to focus on four different viewpoints, aspects which are related to the results obtained by the empirical study. The first approach is to analyse the close relationship between tourism and gastronomy. The second one is to establish a segmentation of the tourists who visit a specific destination, in accordance with the importance they place on gastronomy. The third approach that this research addresses is discovering the socio-demographic profile of the tourists in terms of the importance they place on gastronomy. And the fourth one is determining the tourist's perceived value of the destination, using the importance given to gastronomy for reference.

\subsection{Tourism and Gastronomy}

Gastronomy is a key element in the analysis of the visitor's experience of a tourist destination. Because of this, it is crucial to be aware of the importance that the traveller places on local gastronomy during their stay at a destination (Ellis et al. 2018). In this regard, the relationship between gastronomy and tourism can be quite varied. Therefore, specific tourists do not have any motivation to discover the gastronomy of a place beyond the physiological need to feed themselves. On the other hand, some travellers understand gastronomy as a means of discovering the culture and customs of the place they visit, therefore, they search for a different experience (Ting et al. 2017). Thus, and for this type of visitor, gastronomy becomes the main or secondary motivation when visiting a specific destination.

In recent years, scientific literature that analyses the relationships between tourism and gastronomy has considerably increased (Ellis et al. 2018). Among the work, most recently highlighted in this field are the studies by Timothy (2016), two reports from the World Tourism Organization (UNWTO 2012, 2017) where gastronomic tourism is addressed globally, or the co-ordinated collective work of Dixit (2019). Additionally, two bibliometric analyses completed in this field stand out. In the first analysis, done by Lee and Scott (2015), they point out the importance of 48 papers in this field, published in eight different journals, where Tourism Management and the Journal of Culinary Science and Technology are highlighted. The second analysis, carried out by Okumus et al. (2018), presents a bibliometric analysis of the research in the field of culinary tourism, which shows the exponential evolution in terms of the 
number of articles published in this field and identifies the magazines, universities, and researchers of reference.

Henderson (2009) suggests four lines of research in the field of gastronomic tourism. The first line of research focuses on the analysis of the gastronomic behaviour of the tourist during their stay in a place. The second line of research addresses the study of gastronomy as a tourist product. The third line presents gastronomy as an important instrument in the promotion of a destination, and the fourth line of research deals with determining the economic impact that this type of tourist has on a destination. This study is included in the first line of research that Henderson suggests (Henderson 2009), as it examines the relationship between gastronomy and tourists during their stay in the city of Sucre.

Fields (2002) classifies the motivations that a tourist has to discover a destination's gastronomy into four large groups: physical motivations, cultural motivations, interpersonal motivations, and status and privilege motivations. The first group, physical motivations, deals with satisfying the physiological need that tourists have to feed themselves at a destination. The second group, cultural motivations, deals with analysing the search the tourist conducts in order to better discover the culture of a place through its culinary heritage. The third group, interpersonal motivations, studies the need that every tourist has, as a human being, to socialise with other people and how gastronomy is used as a basic instrument for this socialisation. The fourth group, status and privilege motivations, is framed within the social role that travellers place on their own gastronomic experiences at a destination. All of these motivations may be individual, simultaneous, or even a combination of the four motivations (López-Guzmán et al. 2017).

\subsection{Segmentation of Tourists on the Basis of Gastronomy}

The segmentation of tourists who arrive at a specific location is necessary in order to perform the appropriate management of the place by institutions, both private and public. Additionally, the correct segmentation of tourists allows for the detection of the needs of each of the groups identified so as to, in this way, favour the development of specific tourist products for each one. Therefore, and especially so in the area of gastronomic tourism, it is essential to identify segments of tourists with homogeneous characteristics, due to that fact that tourists visiting one destination are quite different in terms of their interest in culinary gastronomy (Levitt et al. 2017).

In accordance with scientific literature (Kivela and Crotts 2005; McKercher et al. 2008; Björk and Kauppinen-Räisänen 2016; Robinson et al. 2018), it has been observed that visitors with the highest gastronomic motivation have, generally, greater purchasing power. Therefore, these scientific studies confirm that this type of visitor, who is interested in gastronomy, has a higher level of demand in relation to aspects such as the authenticity of local gastronomy or the quality of the ingredients used.

Scientific studies that segment tourists based on their interest in gastronomy are different. Thus, Kivela and Crotts (2005) performed a division of tourists on the basis of three different points: First, the degree of culinary culture of the visitor; second, the tourist's degree of gastronomic motivation as a determining factor when deciding to visit a destination; and third, the degree of gastronomic experience that the tourist seeks. According to these three matters, Kivela and Crotts (2005) classified tourists into two large groups: First, a segment that contains visitors who declare having an important motivation to discover the local cuisine; second, a segment of visitors who show little interest in the local gastronomy, but, on the other hand, are motivated to discover by other attractions of the place.

For their part, McKercher et al. (2008) classify tourists into five groups in terms of their interest in gastronomy: Non-culinary tourist, unlikely culinary tourist, possible culinary tourist, likely culinary tourist, and definitive culinary tourist. In order to carry out this segmentation, the following questions were asked: First, whether the visitor considers themself to be a culinary tourist; second, whether the traveller's motivation is to try the local cuisine or not; and third, if the visitor has, as a main or secondary motivation, the desire to discover gastronomy when deciding on whether to visit a specific place. 
The most relevant research recently conducted in this field is the research of Björk and Kauppinen-Räisänen (2016) and Robinson et al. (2018). Björk and Kauppinen-Räisänen (2016) divide the tourists into three groups according to the degree of interest shown in the local gastronomy: First, experiencers, which is formed by those tourists whose knowledge of the local gastronomy is the main motivation to visit a destination; second, enjoyers, which includes visitors who declare a significant interest in the gastronomy and culinary experiences; and third, survivors, which includes those tourists who do not consider gastronomy to be an attractive element of a destination. For their part, Robinson et al. (2018) gather tourists in terms of activities they do related to gastronomy at a destination, and in agreement with these activities, tourists are segmented into two groups: Experts and those who are unaware. These two groups differ from each other according to what travellers spend on the culinary activities offered in the place they visit.

As previously indicated, this study follows the model of Björk and Kauppinen-Räisänen (2016). In accordance with the scientific literature, the hypothesis to compare would be the following:

Hypothesis $\mathbf{1}_{\mathbf{0}}\left(\mathbf{H} \mathbf{1}_{\mathbf{0}}\right)$. When choosing a destination, tourists display different behaviour towards gastronomy as a relevant factor.

Hypothesis $\mathbf{1}_{\mathbf{1}}\left(\mathbf{H} \mathbf{1}_{\mathbf{1}}\right)$. When choosing a destination, tourists do not display different behaviour towards gastronomy as a relevant factor.

\subsection{Socio-Demographic Profile of the Gastronomic Tourist}

In agreement with Park (2017) and Robinson et al. (2018), it would be necessary to complete a socio-demographic profile of the tourists who visit a specific location according to their interest in its gastronomy. Scientific literature has analysed the socio-demographic profile of the tourists by means of different research. Thus, among other conclusions, it indicates that the most common profile of gastronomic tourists would be those who are between 35 and 45 years of age, with a medium and medium-high income level, and with a high level of education (Correia et al. 2013; Getz et al. 2015; Björk and Kauppinen-Räisänen 2016; Jiménez Beltrán et al. 2016; Levitt et al. 2017). For their part, Correia et al. (2013) indicate that women stated a greater degree of interest in the local gastronomy than men. In this way, it can be concluded that scientific research has observed a very specific profile of a culinary tourist, which can be used to perform appropriate strategic planning of the destinations (Du Rand et al. 2003). One of the aims of this research is to extract the required results in order to discover the socio-demographic profile of those tourists who visit the city of Sucre and who are more interested in the gastronomy of this city.

In accordance with the scientific literature, the hypotheses to compare would be the following:

Hypothesis $\mathbf{2}_{\mathbf{0}}\left(\mathbf{H} \mathbf{2}_{\mathbf{0}}\right)$. Travellers who are the most interested in the local gastronomy are older.

Hypothesis $\left.\mathbf{2}_{\mathbf{1}} \mathbf{( H 2} \mathbf{2}_{\mathbf{1}}\right)$. Interest in the local gastronomy is not higher in those tourists of an advanced age.

Hypothesis $\mathbf{3}_{\mathbf{0}}\left(\mathbf{H} \mathbf{3}_{\mathbf{0}}\right)$. Interest in local cuisine is higher when the visitor has more academic education.

Hypothesis $\left.\mathbf{3}_{\mathbf{1}} \mathbf{(} \mathbf{H} 3_{1}\right)$. Interest in local cuisine is not higher when the visitor has more academic education.

Hypothesis $\mathbf{4}_{\mathbf{0}}\left(\mathbf{H} \mathbf{4}_{\mathbf{0}}\right)$. Travellers with a greater interest in the local gastronomy cause a greater economic impact.

Hypothesis $\mathbf{4}_{\mathbf{1}}\left(\mathbf{H} \mathbf{4}_{\mathbf{1}}\right)$. Travellers with a greater interest in the local gastronomy do not cause a greater economic impact. 


\subsection{Perceived Value of a Destination According to Their Interest in the Local Gastronomy}

Scientific literature analyses gastronomy as an element for promotion and satisfaction on the tourist's part (Pérez-Gálvez et al. 2017). In addition, gastronomy does not only imply a profit for the restaurants but also for shops with local culinary products, or even for the demand of gastronomic products that the tourist will have in their place of residence (Jiménez Beltrán et al. 2016). Additionally, this type of tourism is compatible with the seasonality that occurs in some places as with their sustainable development (Vázquez-Martinez et al. 2019). On the other hand, it is also possible to complement culinary experiences with other related ones, as would be the case for wine tasting in a geographic area, managing, therefore, to attract a higher number of tourists and making this experience something unique and different (Haven-Tang and Jones 2005). However, in order for this experience to be unforgettable, not only is it relevant that there is a significant number of dining establishments (Pérez-Gálvez et al. 2017) but also that the gastronomic variety of a place is perfectly identified with the destination. As such, it is essential at a destination to develop gastronomic strategies that support culinary tradition and innovation (Getz et al. 2015).

In accordance with scientific literature, the hypothesis to compare would be the following:

Hypothesis $\mathbf{5}_{\mathbf{0}}\left(\mathbf{H}_{\mathbf{0}} \mathbf{)}\right.$. The perception that tourists have of a destination in relation to the local gastronomy is significantly different, with tourists who have a higher interest in the local gastronomy being those who have a better perception of the place.

Hypothesis $\mathbf{5}_{\mathbf{1}}\left(\mathbf{H} \mathbf{5}_{\mathbf{1}}\right)$. The perception that tourists have of a destination in relation to the local gastronomy is not significantly different, with tourists who have a higher interest in the local gastronomy being those who have a better perception of the place.

\section{Methodology}

\subsection{Questionnaire Design}

This research is based on field work consistent with the completion of surveys for a representative sample of visitors who come to the area of Sucre. The main objective of this research is to identify the different groups of gastronomic tourists who visit the city, discover their socio-demographic characteristics, and study their assessment and their perception of the gastronomy in Sucre. The questionnaire used in this research is based on different previous research (Björk and Kauppinen-Räisänen 2016; Pérez-Gálvez et al. 2017; López-Guzmán et al. 2017). In order to obtain the definitive survey, it began with an initial ensemble of items and underwent a refinement process divided into four phases: First, a researcher specialised in gastronomy analysed the items proposed; second, the resulting questionnaire was revised by various people responsible for tourist activity in the city: third, the questionnaire was revised by various people responsible for culinary establishments located in the city of Sucre; and fourth, a pre-test was conducted on 50 tourists who were visiting Sucre. The questionnaire was provided in two languages (Spanish and English). Each one of the tourists chose the language of the survey.

The survey is divided into three large blocks. The first collects details about the visitor's stay in Sucre. The second includes details related to the interest that the tourist has in gastronomy and the perception that the visitor has regarding local gastronomy, and the third block shows the details of the socio-demographic profile of the tourists surveyed. The survey used questions with yes/no answers, open and closed answers, and questions with a five-point Likert scale (1 being of little importance and 5 being very important).

\subsection{Data Collection}

The field work was conducted between November 2017 and March 2018 by a team of surveyors linked to the Royal and Pontifical Major University of Saint Francis Xavier of Chuquisaca (Bolivia), 
who performed a personal interview with the tourists. The surveys were conducted in different dining establishments in the historic centre of Sucre, recognised for the importance that they place in their menus on local gastronomy. Additionally, the surveys were conducted on different days and at different times with the aim of obtaining the widest range of visitor profiles possible. A convenience sample was used; a sample generally used in this class of research where the people surveyed are available at a specific place and time (Finn et al. 2000). The approximate time taken for the completion of the survey was $10 \mathrm{~min}$. The number of surveys obtained was 567, from which 529 were valid. The rejection rate for the questionnaire was low and not significant in relation to any variable.

\subsection{Sample and Sampling Error}

This research has the aim of analysing tourists, both national and international, who visited the historic centre of the city of Sucre. The population that is the subject of this research was the number of tourists who stayed overnight in hotel establishments in the city of Sucre in 2017. In this way, and according to the Instituto Nacional de Estadística de Bolivia ("Bolivian National Institute of Statistics"), this figure was 143,294 tourists. As such, and using the number of visitors as a guide, if this research had used simple random sampling, the sampling error for a confidence level of $95 \%$ would be $\pm 4.25 \%$.

\subsection{Data Analysis}

The tabulation and statistical analysis of the data was carried out using the SPSS v.24 computer programme. In order to measure the reliability and the validity of the answers obtained, Cronbach's alpha statistical was applied. Additionally, a multi-variant technique for cluster grouping (K-means clusters) was used with the aim of analysing the similarity among visitors in accordance with their higher or lower interest in the local gastronomy. On the other hand, a discriminant analysis was applied for validating the grouping of different groups obtained in the conglomerate study, as well as different statisticals and measures of association with the aim of obtaining the required information in order to determine the possible association among the variables used in this research, using a table of bi-dimensional contingencies for this. Finally, non-parametric statisticals were used (Kruskal-Wallis' $\mathrm{H}$ statistical and Mann-Whitney's U statistical) in order to assess the possible significant differences among the different resulting groups.

\section{Results and Discussion}

\subsection{Segmentation of the Tourists in Accordance with Their Interest in Gastronomy}

This research is based on the segmentation of the tourists according to the interest the tourists have in the local gastronomy. In order to complete this segmentation, the model of Björk and Kauppinen-Räisänen (2016) was followed. This model is based on the analysis of the responses that tourists give to three questions, which are reflected in Table 1. Cronbach's alpha coefficient presents a value of 0.775 , a value that indicates an important internal consistency among the different elements of the scale. The critical level (p), associated with Friedman's $\chi^{2}$ statistical, is 51.791. As such, it rejects the hypothesis that the means of the elements used are the same.

In the first analysis, two or three segments were obtained. However, and applying a non-hierarchical K-means clustering algorithm, it was determined that the most appropriate choice for the segmentation of tourists depending on their interest in gastronomy was the use of three groups, clusters, or segments. Each one of these groups has been named, according to the model proposed by Björk and Kauppinen-Räisänen (2016), survivors, enjoyers, and experiencers. Table 1 shows that the first group of tourists is formed by $24.2 \%$ of the travellers surveyed. This group presents significantly low registers in the three items and, as such, is formed by visitors who are identified by their low interest in gastronomy. This group is known as survivors. The second segment, known as enjoyers, represents $51.0 \%$ of the sample and has intermediate scores in the three items. This segment includes 
visitors who have a certain interest in local gastronomy. The third group, known as experiencers, represents $24.8 \%$ of those surveyed and has high scores in the three items. In this respect, the visitors grouped in this segment declare a great interest in the local gastronomy.

In this research, Kruskal-Wallis' H statistical has been used to contrast the compared means and to analyse if they are the same among the different groups. However, it does not allow us to specify where the differences shown are to be found and, in order to know what mean differentiates from the other, Mann-Whitney's U statistical was used.

Table 1. Characterisation clusters from gastronomy attitude.

\begin{tabular}{|c|c|c|c|c|c|}
\hline \multirow{2}{*}{ Gastronomy Attitude } & \multicolumn{3}{|c|}{ Food Clusters } & \multicolumn{2}{|c|}{ H-Kruskal-Wallis } \\
\hline & Survivors & Enjoyers & Experiencers & $x^{2}$ & Sig. \\
\hline $\begin{array}{l}\text { How would you rate your } \\
\text { knowledge on gastronomy? }\end{array}$ & $1.99\left(^{*}\right)$ & $3.40\left(^{*}\right)$ & $4.36\left(^{*}\right)$ & 298.552 & $<0.000$ \\
\hline $\begin{array}{l}\text { How would you rate your interest } \\
\text { in gastronomy? }\end{array}$ & $1.93\left(^{*}\right)$ & $3.11\left(^{*}\right)$ & $3.91\left(^{*}\right)$ & 298.405 & $<0.000$ \\
\hline $\begin{array}{l}\text { How much has Sucre's gastronomy } \\
\text { influenced your visit to the city? }\end{array}$ & $2.40\left(^{*}\right)$ & $3.88\left(^{*}\right)$ & 3.98 & 196.502 & $<0.000$ \\
\hline
\end{tabular}

Results allow for the comparison of the first research hypothesis: tourists show different attitudes towards gastronomy as a variable interest in the choice of a destination $\left(\mathrm{H}_{0}\right)$. These previous studies have identified, at least, a segment of tourists with a special interest in the destination's gastronomy and another one where this variable is indifferent. In our research, the first group are referred to as experiencers (following the segmentation model of Björk and Kauppinen-Räisänen 2016). The existence of this type of gastronomic tourist has also been noted in scientific literature. Hjalager (2004) calls them experimental gastronomy tourists and McKercher et al. (2008) names them definite culinary tourists. In the case of those who are not interested in the destination's gastronomy, which, in this research, we have called survivors (following the model indicated above); other studies name them differently. Thus, Hjalager (2004) calls the tourists 'recreational' while Thompson and Prideaux (2009) describe them as 'not interested'.

Additionally, the indicated result of tourist segmentation has been subject to validation by means of a discriminant analysis, which allows for the discovery of the percentage of individuals who are correctly assigned to each cluster. In this sense, Table 2 allows us to observe, by means of a contingency table, the subjects belonging to each group and those ones who are classified appropriately, according to the analysis. As can be seen in the table, the grouping into three segments correctly classifies $99.2 \%$ of the people surveyed.

Table 2. Discriminant analysis synthesis.

\begin{tabular}{ccccc}
\hline & \multicolumn{2}{c}{ Predicted Membership Clusters } & \multirow{2}{*}{ Total } \\
\cline { 2 - 4 } & Survivors & Enjoyers & Experiencers & \\
\hline Survivors & 124 & Count & 128 \\
Enjoyers & 0 & 0 & 4 & 270 \\
Experiencers & 0 & 270 & 131 & 131 \\
\hline Survivors & $96.9 \%$ & 0 & $0.0 \%$ & $100 \%$ \\
Enjoyers & $0.0 \%$ & $100 \%$ & $3.1 \%$ & $100 \%$ \\
Experiencers & $0.0 \%$ & $0.0 \%$ & $100 \%$ & $100 \%$ \\
\hline
\end{tabular}

Source: Own elaboration. 


\subsection{Socio-Demographic Profile of the Visitors}

Of the 529 valid surveys completed by visitors to the city of Sucre, 55.0\% were from men and $45.0 \%$ were from women, with there being no significant differences due to gender. In Table 3, we can note that more than $80 \%$ of the sample is under the age of 40 . As such, it deals with young tourists. There are significant differences in terms of the groups considered (Kruskal-Wallis' $\mathrm{H}$ statistical = 17.624; $p=0.000$ ). However, comparing these results with previous studies (Pérez-Gálvez et al. 2017), the percentage of old age tourists is higher in the segment that shows less interest in the local gastronomy. As a result, the suggested research hypothesis is not confirmed: travellers with a higher interest in gastronomy are older. $\left(\mathrm{H}_{2}\right)$. Therefore, the interest in local gastronomy is not higher in tourists who are of an advanced age $\left(\mathrm{H} 2_{\mathrm{a}}\right)$. In this sense, the youth of the tourists specified in the sample means that Sucre's gastronomy may have a high level for promotion among this group that, additionally, are tourists who are regular and active users of social media. All of this means that the digital marketing strategies that the tourist managers of the city may initiate will appropriately reach a public target that is quite used to moving in virtual environments, boosting its effectiveness at the same time.

Table 3. Sociodemographic profile of foreingn tourists in Sucre.

\begin{tabular}{|c|c|c|c|c|c|}
\hline \multirow{2}{*}{ Variables } & \multirow{2}{*}{ Categories } & \multicolumn{3}{|c|}{ Food Clusters } & \multirow{2}{*}{ Total } \\
\hline & & Survivors & Enjoyers & Experiencers & \\
\hline \multirow{2}{*}{$\begin{array}{l}\text { Gender } \\
(\mathrm{N}=529)\end{array}$} & Man & $56.2 \%$ & $55.6 \%$ & $52.7 \%$ & $55.0 \%$ \\
\hline & Woman & $43.8 \%$ & $44.4 \%$ & $47.3 \%$ & $45.0 \%$ \\
\hline \multirow{5}{*}{$\begin{array}{c}\text { Age } \\
(N=529)\end{array}$} & Less than 30 years & $43.0 \%$ & $44.8 \%$ & $63.4 \%$ & $49.0 \%$ \\
\hline & 30-39 years & $34.4 \%$ & $35.2 \%$ & $28.2 \%$ & $33.3 \%$ \\
\hline & $40-49$ years & $9.4 \%$ & $11.9 \%$ & $3.8 \%$ & $9.3 \%$ \\
\hline & 50-59 years & $4.7 \%$ & $6.7 \%$ & $4.6 \%$ & $5.7 \%$ \\
\hline & 60 years or more & $8.5 \%$ & $1.4 \%$ & - & $2.7 \%$ \\
\hline \multirow{4}{*}{$\begin{array}{c}\text { Level of } \\
\text { Education } \\
(\mathrm{N}=529)\end{array}$} & Primary education & $0.8 \%$ & $1.1 \%$ & $0.8 \%$ & $0.9 \%$ \\
\hline & Secundary education & $14.8 \%$ & $17.8 \%$ & $18.3 \%$ & $17.2 \%$ \\
\hline & University education & $54.7 \%$ & $61.1 \%$ & $52.7 \%$ & $57.5 \%$ \\
\hline & Master/PhD & $29.7 \%$ & $20.0 \%$ & $28.2 \%$ & $24.4 \%$ \\
\hline \multirow{8}{*}{$\begin{array}{l}\text { Professional } \\
\text { categories } \\
\mathrm{N}=529 \text { ) }\end{array}$} & Freelance & $28.9 \%$ & $30.4 \%$ & $29.0 \%$ & $29.7 \%$ \\
\hline & Public services & $13.3 \%$ & $17.4 \%$ & $18.3 \%$ & $16.6 \%$ \\
\hline & Employed & $15.6 \%$ & $14.4 \%$ & $16.0 \%$ & $15.0 \%$ \\
\hline & Student & $10.2 \%$ & $16.3 \%$ & $15.3 \%$ & $14.6 \%$ \\
\hline & Businessman & $12.5 \%$ & $9.3 \%$ & $11.5 \%$ & $10.6 \%$ \\
\hline & Unemployed & $11.7 \%$ & $8.1 \%$ & $9.9 \%$ & $9.5 \%$ \\
\hline & Retired & $5.50 \%$ & $2.20 \%$ & - & $2.5 \%$ \\
\hline & Housewife & $2.30 \%$ & $1.90 \%$ & - & $1.5 \%$ \\
\hline \multirow{4}{*}{$\begin{array}{c}\text { Origin of } \\
\text { tourist } \\
(N=529)\end{array}$} & South America & $56.9 \%$ & $71.2 \%$ & $59.3 \%$ & $64.7 \%$ \\
\hline & Europe & $26.7 \%$ & $14.2 \%$ & $20.0 \%$ & $18.8 \%$ \\
\hline & North America & $14.1 \%$ & $13.0 \%$ & $17.6 \%$ & $14.3 \%$ \\
\hline & Others & $2.3 \%$ & $1.6 \%$ & $3.1 \%$ & $2.2 \%$ \\
\hline \multirow{6}{*}{$\begin{array}{l}\text { Income } \\
(N=529)\end{array}$} & Less than $\$ 500$ & $22.7 \%$ & $18.9 \%$ & $21.4 \%$ & $20.4 \%$ \\
\hline & From $\$ 500$ to $\$ 1000$ & $16.4 \%$ & $30.7 \%$ & $28.2 \%$ & $26.7 \%$ \\
\hline & From $\$ 1001$ to $\$ 1500$ & $18.8 \%$ & $16.3 \%$ & $13.0 \%$ & $16.1 \%$ \\
\hline & From $\$ 1501$ to $\$ 2500$ & $19.5 \%$ & $14.4 \%$ & $14.5 \%$ & $15.7 \%$ \\
\hline & From $\$ 2501$ to $\$ 3500$ & $12.5 \%$ & $11.1 \%$ & $10.7 \%$ & $11.3 \%$ \\
\hline & More than $\$ 3500$ & $10.1 \%$ & $8.6 \%$ & $12.2 \%$ & $9.8 \%$ \\
\hline
\end{tabular}

Source: Own elaboration.

The education level of the visitors is high (Table 3), as eight out of every ten tourists surveyed has a university degree or a post-graduate degree. If the tourist's education level is considered in relation to 
age, significant differences are detected. Older tourists have a higher academic level and, at a younger age, the number of tourists with post-graduate studies is lower (gamma coefficient $=0.284 ; p=0.000$ ). However, no differences have been detected in gastronomic segments (Kruskal-Wallis' $\mathrm{H}$ statistical = 3.958; $p=0.136)$. Accordingly, the hypothesis $\left(\mathrm{H}_{0}\right)$ is not proven: the interest in local gastronomy is greater when the visitor has a higher education level (Kivela and Crotts 2005; McKercher et al. 2008; Jiménez Beltrán et al. 2016; Levitt et al. 2017). This proves the hypothesis ( $\left.\mathrm{H} 3_{\mathrm{a}}\right)$, which indicates that interest in the local gastronomy is not greater when the visitor has a higher education level. This result, as well as the youth of the tourists who visit Sucre, means that the promotion of this Latin American destination should not be limited to the traditional groups of older people and people who have a higher level of education. Thus, the possibilities of improving tourists' perspectives of the city, on the basis of its rich cuisine, are greater and more diverse than other destinations with traditional culinary itineraries.

In terms of the place of origin, $50.5 \%$ of the tourists who visit Sucre are Bolivian and $49.5 \%$ are foreigners. The national tourists come from, essentially, four cities: Potosí (26.6\%), Santa Cruz (24.7\%), Tarija (13.1\%), and La Paz (12.0\%). With regards to foreign tourists, Latin American (34.4\%) and European (34.0\%) tourists stand out, followed by North Americans (29.0\%). Among the European visitors, those coming from France $(27.1 \%)$, Germany $(24.7 \%)$, and Spain $(14.7 \%)$ are highlighted. The analysis of clusters indicates a greater presence of foreigners in the experiencers segment, that is to say, the group that has a greater interest in gastronomy as a motivation for travelling (Kruskal-Wallis' H statistical $=7.511 ; p=0.023)$.

Regarding the matter of who the surveyed tourists travel with, the younger visitors (under the age of 40) generally travel with colleagues or friends. On the other hand, visitors between the ages of 40 and 59 travel with their partners and children. Visitors who travel alone are under the age of 30 (contingency coefficient $=0.378 ; p=0.000$ ).

In relation to the monthly income level of the tourists surveyed, stated in American dollars, $47.1 \%$ of those surveyed do not earn more than 1000 dollars a month, while $21.1 \%$ earn more than 2500 dollars. In a rough sense, the visitors to Sucre have a medium-low purchasing power as only four out of every ten tourists surveyed has an income greater than 1500 dollars a month. In this regard, there are no significant differences in terms of the income level regarding the gastronomic interest of the tourist (Kruskal-Wallis' H statistical $=1.144 ; p=0.564$ ). However, it is relevant to observe that the average income level of tourists in the segment known as survivors is $6 \%$ higher than the overall average and $5 \%$ higher than that declared by tourists in the segment known as experiencers. Notwithstanding, the greater purchasing power of the tourists known as survivors does not lead to them spending more and, in this respect, there are no differences among the different groups (Kruskal-Wallis' H statistical = $2.725 ; p=0.256)$.

The average daily spend per person is 50 dollars, with this being greater among tourists known as enjoyers (52 dollars). Because of this, the hypothesis $\left(\mathrm{H}_{0}\right)$ regarding travellers with a greater interest in local gastronomy having a higher economic impact is not confirmed (Fields 2002; Du Rand et al. 2003). In this case, $\mathrm{H}_{\mathrm{a}}$ is confirmed; travellers with a greater interest in local gastronomy do not have a higher economic impact. In any case, the income derived from tourist activity is usually reinvested, in a greater or lesser amount, in the local community economy of the destination through the creation of employment, the diversification of activities, the sale of articles and services to tourists, and the increase in other assistance sectors such as hospitality, trade, leisure, and transport. Because of this, the culinary resources of a destination may be the key for the development of sustainable tourism (Timothy and Ron 2013), making it more attractive and diversified (Hillel et al. 2013).

In terms of overnight stays, only $6.2 \%$ of the tourists surveyed did not stay overnight in Sucre and $75.3 \%$ did so for between two and seven nights. No significant differences have been detected among the different segments, obtaining an average overnight stay index of 4.3 nights (Kruskal-Wallis' $\mathrm{H}$ statistical $=1.848 ; p=0.397)$. Regarding the type of accommodation used, the one most in demand is a one star hotel, followed by the house of friends and/or family members, or two or three star hotels (only 
two out of every ten tourists stay overnight in hotels with two or more stars). As such, it can be noted that these results are in agreement with the income level and the average daily spend of the visitors.

\subsection{Perceived Assessment of the Gastronomy}

In order to identify this destination's strengths and areas for improvement, an analysis regarding the relationship between the attributes and the aspects of the local gastronomy was performed (Table 4). The assessment of any of these aspects is not as high as the general satisfaction level, given that it deals with extremely concise aspects whose assessment includes personal and specific factors. The best rated attributes are the following: "Experience with the local gastronomy", "prices", and "service and hospitality". On the other hand, those with the worst scores were the following: "Innovation and new tastes in the dishes", "atmosphere", and "facilities". These results allow the public and private managers of the tourist area of the city to design strategies that boost the most-valued attributes of its gastronomy and, at the same time, combat those that cause dissatisfaction for the tourist or, at least, do not cause appropriate satisfaction that weakens loyalty to the destination, in this case, on the basis of its gastronomy.

Table 4. Assessment of the attributes of the gastronomy of Sucre.

\begin{tabular}{ccc}
\hline Gastronomic Attributes of Sucre & Average & Rank \\
\hline Experience with the local gastronomy & 3.83 & 1 \\
Prices & 3.69 & 2 \\
Service and hospitality & 3.68 & 3 \\
Food quality & 3.61 & 4 \\
Innovation and new flavours in the dishes & 3.54 & 5 \\
Atmosphere & 3.46 & 6 \\
Facilities & 3.40 & 7 \\
\hline Alpha de Cronbach & \multicolumn{2}{c}{0.775} \\
\hline
\end{tabular}

Source: Own elaboration.

Regarding the characterisation of the segments related to gastronomy (Table 5), an assessment of the gastronomic attributes of the city of Sucre is detected that is different depending on the type of tourist (Kim et al. 2013; Timothy and Ron 2013; Pérez-Gálvez et al. 2017; López-Guzmán et al. 2017). Thus, and according to the results obtained, aspects such as "experience with the local gastronomy", "quality of the dishes", and "service and hospitality" are assessed with a greater score on the part of the group of visitors with a higher gastronomic interest, that is to say, the segment known as experiencers $\left(\mathrm{H} 5_{0}\right)$.

Table 5. Characterization of the clusters on relation to gastronomy.

\begin{tabular}{|c|c|c|c|c|c|}
\hline \multirow{2}{*}{ Gastronomic Attributes of Sucre } & \multicolumn{3}{|c|}{ Food Clusters } & \multicolumn{2}{|c|}{ H-Kruskal Wallis } \\
\hline & Survivors & Enjoyers & Experiencers & $x^{2}$ & Sig. \\
\hline Experience with the local gastronomy & $3.42(*)$ & 3.88 & 4.00 & 26.336 & $<0.000$ \\
\hline Prices & $3.38\left(^{*}\right)$ & 3.78 & 3.83 & 20.346 & $<0.001$ \\
\hline Service and hospitality & 3.45 & 3.67 & 3.80 & 9.493 & $<0.009$ \\
\hline Food quality & $3.18(*)$ & $3.69\left(^{*}\right)$ & $3.86(*)$ & 44.672 & $<0.000$ \\
\hline Innovation and new flavours in the dishes & $3.17\left(^{*}\right)$ & 3.58 & 3.69 & 22.723 & $<0.000$ \\
\hline Atmosphere & $3.22\left({ }^{*}\right)$ & 3.50 & 3.55 & 7.332 & $<0.026$ \\
\hline Facilities & 3.22 & 3.44 & 3.48 & 5.764 & $<0.056$ \\
\hline Average & $3.29\left(^{*}\right)$ & 3.68 & 3.71 & 36.569 & $<0.000$ \\
\hline
\end{tabular}

$\left(^{*}\right)$ These values present significant differences in three of four of the means clusters. The Mann-Whitney U-test was applied to test for the significant differences between the different means. Source: Own elaboration. 


\section{Conclusions}

One of the main conclusions of this study is that local gastronomy plays an essential role as a tool of attraction for a specific type of tourist. Therefore, the study concludes that visitors present different attitudes towards the local gastronomy as a variable of tourist attraction. As such, and in agreement with the interest that tourists have regarding local gastronomy, it has detected empirical evidence regarding the existence of three different segments of tourists who, following the model of Björk and Kauppinen-Räisänen (2016), are known as survivors, enjoyers, and experiencers. Of the three segments obtained, gastronomy plays an important role for one of them, that known as experiencer.

The main contribution of this research is to show evidence of how gastronomy has become an important resource for tourist attraction in mainly cultural destinations. Therefore, it contributes to strengthening the studies carried out regarding the relationship between tourism and gastronomy in Latin America. Similarly, this research also offers practical implications. The main practical contribution is a greater and better understanding of the differentiated characteristics of the traveller segments and their assessment of Sucre's gastronomy, with the aim of being able to design a tourist offer that is better adapted to their needs. This contributes to conceiving tourist products that best satisfy the needs of the traveller and, at the same time, are compatible with the sustainable management of local gastronomy. In this sense, and with the aim of boosting local gastronomic development, it is necessary to establish measures that favor innovation and new flavors in dishes of the city's culinary establishments. Furthermore, the promotion and presentation of culinary resources shoud be performed in a differentiated way; in order to do so, a varied number of establishments where tourists can enjoy their specialities is required.

The main restriction of this research would be the time period in which the field work was carried out. Because of this, a future line of research is suggested that would expand the field work to include a longer time period that addresses the different seasons of the year with the aim of conducting a comparative study with the results obtained in field work performed in other months.

Author Contributions: M.J.M.-V., G.G.C., P.A.F.J. and F.G.S.C. conceptualized the work and ideated the structure. They analyzed the literature, interpreted and curated the data, and wrote the manuscript. The authors read and revised the manuscript several times.

Funding: This research received no external funding.

Acknowledgments: The authors of this paper wish to thank Mgr. Ivan Tolavi Soruco, member of the Faculty of Economics at Royal Mayor and Pontifical University of San Francisco Xavier in Chuquisaca, for his support in conducting this research.

Conflicts of Interest: The authors declare no conflict of interest.

\section{References}

Björk, Peter, and Hannele Kauppinen-Räisänen. 2016. Local food: A source for destination attraction. International Journal of Contemporary Hospitality Management 28: 177-94. [CrossRef]

Correia, Antonia, Metin Kozak, and João Ferradeira. 2013. From tourist motivations to tourist satisfaction. International Journal of Culture, Tourism and Hospitality Research 7: 411-24. [CrossRef]

Dixit, Saurabh Kumar. 2019. The Routledge Handbook of Gastronomic Tourism. Abingdon: Routledge.

Du Rand, Gerrie E., Ernie Heath, and Nic Alberts. 2003. The role of local and regional food in destination marketing: A South African situation analysis. Journal of Travel and Tourism Marketing 14: 37-52. [CrossRef]

Ellis, Ashleigh, Eerang Park, Sangkyun Kim, and Ian Yeoman. 2018. What is food tourism? Tourism Management 68: 250-63. [CrossRef]

Fields, Kevin. 2002. Demand for the gastronomy tourism product. Motivational factors. In Tourism and Gastronomy. Edited by Anne-Mette Hjalager and Greg Richards. London: Routledge, pp. 36-50.

Finn, Mick, Mike Walton, and Martin Elliott-White. 2000. Tourism and Leisure Research Methods: Data Collection, Analysis and Interpretation. Harlow: Pearson Education. 
Getz, Donald, Tommy Andersson, Sanja Vujicic, and Richard N. S. Robinson. 2015. Food events in lifestyle and travel. Event Management 19: 407-19. [CrossRef]

Haven-Tang, Claire, and Eleri Jones. 2005. Using local food and drink to differentiate tourism destinations through a sense of place: A story from Wales-Dining ar Mommouthshire's Great Table. Journal of Culinary Science and Technology 4: 69-86. [CrossRef]

Henderson, Joan C. 2009. Food tourism reviewed. British Food Journal 111: 317-26. [CrossRef]

Hillel, David, Yaniv Belhassen, and Amir Shani. 2013. What makes a gastronomic detination attractive? Evidence from the Israeli Negev. Tourism Management 36: 200-9. [CrossRef]

Hjalager, Anne Mette. 2004. What do tourists eat and why? Towards a sociology of gastronomy and tourism. Tourism 52: 195-201.

Jiménez Beltrán, Javier, Tomás López-Guzmán, and Francisco González Santa-Cruz. 2016. Gastronomy and tourism: Profile and motivation of international tourism in the city of Córdoba, Spain. Journal of Culinary Science y Technology 14: 350-66. [CrossRef]

Kim, Yeong Gug, Anita Eves, and Caroline Scarles. 2013. Empirical verification of a conceptual modelo of local consumption at a tourist destination. International Journal of Hospitality Management 33: 484-89. [CrossRef]

Kivela, Jakša, and John C. Crotts. 2005. Gastronomy tourism: A meaningful travel market segment. Journal of Culinary Science and Technology 4: 39-55. [CrossRef]

Lee, Kuan-Huei, and Noel Scott. 2015. Food tourism reviewed using the paradigm funnel approach. Journal of Culinary Science and Technology 25: 61-70. [CrossRef]

Levitt, Jamie A., Pei Zhang, Robin B. DiPietro, and Fang Meng. 2017. Food tourist segmentation: Attitude, behavioral intentions and travel planning behavior base on food involvement and motivation. International Journal of Hospitality \& Tourism Administration 20: 1-27. [CrossRef]

López-Guzmán, Tomás, Claudia Patricia Uribe Lotero, Jesús Claudio Pérez-Gálvez, and Ingrid Ríos Rivera. 2017. Gastronomic festivals: Attitude, motivation and satisfaction of the tourist. British Food Journal 119: 267-83. [CrossRef]

McKercher, Bob, Fevzi Okumus, and Bendegul Okumus. 2008. Food Tourism as a Viable Market Segment: It's All How You Cook the Numbers! Journal of Travel y Tourism Marketing 25: 137-48. [CrossRef]

Nelson, Velvet. 2016. Peru's image as a culinary destination. Journal of Cultural Geography 33: 208-228. [CrossRef]

Okumus, Bendegul, Mehmet Ali Koseoglu, and Forest Ma. 2018. Food and gastronomy research in tourism and hospitality: A bibliometric analysis. International Journal of Hospitality Management 73: 64-74. [CrossRef]

Park, Kendall. 2017. Ethnic Foodscapes: Foreign cuisines in the United States. Food, Culture y Society 20: 365-93. [CrossRef]

Pérez-Gálvez, Jesús Claudio, Marlene Jaramillo Granda, Tomás López-Guzmán, and Jose Reinoso Coronel. 2017. Local gastronomy, culture and tourist, sustainable cities: The behavior of the American tourist. Sustainable Cities and Society 32: 604-12. [CrossRef]

Privitera, Donatella, Adrian Nedelcu, and Virgil Nicula. 2018. Gastronomic and food tourism as an economic local resource: Case studies from Romania and Italy. GeoJournal of Tourism and Geosites 21: 143-57.

Robinson, Richard N. S., Don Getz, and Sara Dolnicar. 2018. Food tourism subsegments: A data-driven analysis. International Journal of Tourism Research 20: 367-77. [CrossRef]

Thompson, Michelle, and Bruce Prideaux. 2009. Developing a food and wine segmentation and classifying destinations on the basis of their food and wine sectors. Advances in Hospitality and Leisure 5: 163-183.

Timothy, Dallen J. 2016. Heritage Cuisines: Traditions, Identities and Tourism. Abingdon: Routledge.

Timothy, Dallen J., and Amos S. Ron. 2013. Understanding heritage cuisines and tourism: Identity, image, authenticity, and change. Journal of Heritage Tourism 8: 99-104. [CrossRef]

Ting, Hiram, Sharon Rebecca Tan, and Alexandra Nastassia John. 2017. Consumption intention towards ehnic food. Determinants of dayak food choice by Malaysians. Journal of Ethnic Foods 4: 21-27. [CrossRef]

Tsai, Chen-Tsang Simon, and Yao-Chin Wang. 2017. Experiential value in branding food tourism. Journal of Destination Marketing y Management 6: 56-65. [CrossRef]

UNWTO. 2012. Global Report on Food Tourism. Madrid: UNWTO. 
UNWTO. 2017. Second Global Report on Food Tourism. Madrid: UNWTO.

Vázquez-Martinez, Ulpiano J., Carlos Sanchís-Pedregosa, and Antonio L. Leal-Rodríguez. 2019. Is gastronomy a relevant factor for sustainable tourism? An empirical analysis of Spain country brand. Sustainability 11: 2696. [CrossRef]

(c) (C) 2019 by the authors. Licensee MDPI, Basel, Switzerland. This article is an open access article distributed under the terms and conditions of the Creative Commons Attribution (CC BY) license (http://creativecommons.org/licenses/by/4.0/). 